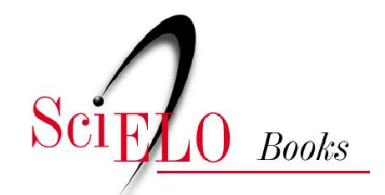

\title{
O absenteísmo escolar e sua regulamentação
}

\author{
Suziane Santana de Vasconcellos \\ Carmem Lúcia Guimarães de Mattos
}

VASCONCELLOS, SS., and MATTOS, CLG. O absenteísmo escolar e sua regulamentação. In MATTOS, CLG., and CASTRO, PA., orgs. Etnografia e educação: conceitos e usos [online]. Campina Grande: EDUEPB, 2011. pp. 271-296. ISBN 978-85-7879-190-2. Available from SciELO Books <http://books.scielo.org>.

\section{@)(1)(9)}

All the contents of this work, except where otherwise noted, is licensed under a Creative Commons Attribution-Non Commercial-ShareAlike 3.0 Unported.

Todo o conteúdo deste trabalho, exceto quando houver ressalva, é publicado sob a licença Creative Commons Atribuição Uso Não Comercial - Partilha nos Mesmos Termos 3.0 Não adaptada.

Todo el contenido de esta obra, excepto donde se indique lo contrario, está bajo licencia de la licencia Creative Commons Reconocimento-NoComercial-CompartirIgual 3.0 Unported. 


\title{
O absenteísmo escolar e sua regulamentação
}

\author{
Suziane Santana de Vasconcellos \\ Carmen Lucia Guimarães de Mattos
}

Como parte da pesquisa Fracasso escolar: gênero e pobreza (MATTOS, 2008-2010) este capítulo apresenta resultados de trabalho final de curso $^{1}$ desenvolvidos no interior do Grupo de Pesquisa Etnografia e Exclusão do Núcleo de Etnografia em Educação (netEDU/ ProPEd/UERJ). É uma pesquisa de abordagem etnográfica que observou durante o ano letivo de 2008 uma classe da $1^{\text {a }}$ série do ensino fundamental que era constituída por alunos e alunas repetentes e multirepetentes.

Na classe de repetentes da turma C, na Escola Municipal João Pedro II, a falta de alunos na sala de aula é um tema recorrente e este capítulo apresenta os estudos que abordam o absenteísmo de alunos (IRELAND, 2007; SOUSA, 2003; NOGUEIRA, 2006; SILVEIRA, 2007; VIANA et al 2007; SOUSA, 2004; CASTELEIRO, 2007); a regulamentação sobre o absenteísmo e suas implicações para o aluno; além dos dados empíricos que ilustram com as falas dos participantes os argumentos sobre o absenteísmo entre os alunos.

O termo absenteísmo é encontrado usualmente na área de administração e é empregado para avaliar a rotatividade de funcionários nas empresas, determinando assim o desempenho

1 Este capítulo foi modificado para fins de publicação neste livro, originalmente é parte da dissertação da mestrado intitulada "A classe de repetentes: um estudo etnográfico" defendida em 2010 pela autora e orientada pela co-autora. 
dos mesmos. Está associado ainda a possíveis problemas em um determinado segmento da empresa, espaços em que o absenteísmo é mais frequente entre os funcionários, servindo para identificar as falhas e os ajustes necessários ao segmento.

Embora ainda pouco comum no contexto educacional, esta expressão vem se tornando cada vez mais frequente na literatura da área. Não raro, o termo é utilizado como sinônimo para 'falta às aulas'. Entretanto, um olhar mais cuidadoso sobre o conceito revela que existem variações para o entendimento do mesmo.

De acordo com Faro (2007) o absenteísmo escolar

constitui por si um problema individual grave na medida em que representa um entrave ao sucesso educativo de cada aluno. Pode conduzir mais tarde a situações de abandono escolar e a situações de delinqüência e exclusão social levando o problema para a esfera da questão social. [...] O absenteísmo escolar, [é] entendido como a falta injustificada de comparecimento às aulas por parte de um aluno (REID, 1981). [...] quando estas faltas de assistência se sucedem de forma reiterada ou se prolongam no tempo, o ritmo de aprendizagem do aluno é afetado e, inevitavelmente, começam a surgir problemas de insucesso escolar que, se não forem solucionados rapidamente, podem conduzir a situações de abandono. [... ] o absenteísmo escolar [...] constitui um dos principais fatores que contribui para o aparecimento de situações de marginalidade, delinquência e analfabetismo (GALLOWAY; SEYD; BALL, 1978). [...] quando o absenteísmo escolar obedece a fatores de tipo social ou familiar, como ocorre na maioria dos casos, então a solução para o problema converte-se num assunto complexo e, por vezes, de difícil solução (Orr, 1987). [...] um aluno que convive num seio de uma família desestruturada, ou imerso num ambiente social onde coexistem problemas sociais graves, como dependências, 
prostituição, delinquência, miséria, tem uma maior probabilidade de vir a engrossar as estatísticas do absenteísmo escolar (FORTIN; ROYER; POTVIN; MARCOTTE; JOLY, 2001). Uma criança ou um adolescente, que tem que se preocupar diariamente por conseguir o seu próprio sustento ou que se desenvolve num ambiente onde o nível educativo ou formativo da pessoa não é valorizado, dificilmente pode sentir-se atraído pela escola, que não oferece resultados tangíveis em curto prazo (FORQUIN, 1985) [...] a maioria destes alunos provêem de ambientes marginais ou de zonas urbanas deprimidas e sofrem graves carências econômicas e sociais (FARO, 2007, p. 6).

Faro (2007) elenca fatores intrínsecos e extrínsecos que podem levar o aluno ao absenteísmo. Dentre os fatores intrínsecos são citados: a preparação acadêmica anterior, a saúde física e o equilíbrio pessoal, o grau de integração na escola e a satisfação acadêmica, as condutas problemáticas, o profundo desinteresse, dentre outros (idem p.12). Os extrínsecos, explica o autor, de acordo com Gilly (1986 apud FARO, 2007) envolvem:

Variáveis familiares: nível socioeconômico, cultural e acadêmico dos progenitores; qualidade da relação entre os membros da família, valor atribuído à escolaridade e ao trabalho, valores morais, interesse dos pais pela educação dos filhos;

Variáveis atribuíveis à dinâmica da própria escola: sistema organizativo e de coordenação, estilos de ensino dos professores, clima de convivência, ambiente percepcionado na turma e fora dela;

Variáveis referentes ao currículo: se este se apresenta atrativo na sua formulação, na sua prática, etc. (GILLY, 1986, apud FARO, 2007, p. 12). 
O absenteísmo escolar vem sendo citado, inúmeras vezes, por Abramovay, em seus estudos sobre a violência escolar (ABRAMOVAY; RUAS, 2002). Nesse contexto a autora destaca a origem do termo, definido a partir da área de administração, associando o absenteísmo às violências da e na escola para com os alunos; a dificuldade de registro e controle pelos professores e autoridades sobre as faltas às aulas; a preconceituosa correlação do problema à família do aluno e a relação direta entre faltas escolares e fracasso escolar, delinquência e pobreza. A autora afirma que:

riscos relacionados à violência simbólica, dos quais poderíamos destacar o absenteísmo e fatores relacionados ao fracasso escolar, tais como o abandono da escola. É importante ressaltar que o absenteísmo frente a uma condição de violência social manifesta, também se associa a fatores de desigualdade social, [...] Sob o ponto de vista administrativo, o absenteísmo vem sendo definido (CHOUQUET, 1993) como um comportamento centrado na repetição de faltas voluntárias às aulas. No caso brasileiro, o Ministério da Educação trabalha a questão de forma aleatória considerando absenteístas, os alunos com determinado número de falta às aulas registradas pelos diários de classe dos professores. [...] Devido às dificuldades sistemáticas de mensurar a incidência e manifestações do absenteísmo dentro da escola e suas possíveis correlações com o fracasso escolar, tem-se estabelecido uma tendência preconceituosa em buscar na família, em especial famílias de baixa renda, os verdadeiros culpados por seus maiores níveis de incidência, reproduzindo assim perspectivas simplistas entre pobreza, delinquência juvenil e fracasso escolar (ABRAMOVAY s/d, p. 13-14).

Uma pesquisa coordenada por Ireland (2007) aponta os desafios enfrentados pelas escolas em todo o Brasil para ensinar seus alunos a ler e escrever. Em sua apresentação o trabalho 
questiona a finalidade da reprovação e aponta a desistência, a repetição e o absenteísmo como parte do 'drama brasileiro' para escolarizar seus alunos. A autora questiona:

Como se poderá entender que uma criança de seis anos de idade, no atual Ensino Fundamental de nove anos, seja uma fracassada ao fim da primeira série? Como se poderá explicar a essa criança, aos seus pais e responsáveis e à sociedade o significado da reprovação, do insucesso e da necessidade de repetir todo o ano de estudos realizados? Esta é uma das faces do drama brasileiro que se manifesta, entre outros aspectos, na desistência dos alunos ao longo dos períodos letivos ou entre eles, na repetição e na perseverança dos estudos, em média por longo tempo, e pelo absenteísmo (IRELAND, 2007, p. 17).

Mais adiante a autora associa a reprovação, a evasão e o absenteísmo entre os alunos, como um indicador de exclusão social:

Sabe-se que dificuldades detectadas na educação básica estão relacionadas com problemas que vão se acumulando desde o início da escolarização de muitas crianças, aqui e ali reveladas por sinais como a reprovação, o abandono da escola e o absenteísmo, fenômenos esses que já se sabe serem também associados ao modo de funcionamento da escola e da sociedade que a comporta. Mas, na medida em que o aluno não consegue desenvolver, ao longo de sua trajetória escolar, determinadas habilidades que lhe permitam enfrentar as tarefas e exigências da sociedade e do mundo do trabalho contemporâneos, ele provavelmente será excluído da sociedade. Nesse sentido, a melhora do desempenho escolar tem uma conotação que vai muito além dos muros da escola (idem, p. 19). 
Portanto, o absenteísmo entre alunos e professores revelase como uma das dificuldades enfrentadas pelas escolas. Mecanismos de controle, tanto para os professores quanto para os alunos, não tem garantido a frequência desses alunos, nem um maior compromisso profissional por parte dos professores em relação às suas faltas. Entretanto, enquanto o absenteísmo entre os professores é interpretado pela escola como um problema a ser resolvido pelos sistemas de ensino (federal, estadual e municipal), entre os alunos, ele é entendido como um problema a ser resolvido pela escola, pelos pais e por instâncias do poder público judiciário.

A impressão que se tem é a de que a presença dos alunos nas escolas, por si só, poderia garantir a sua escolarização, independentemente da presença do professor. Os diversos mecanismos que regulamentam o absenteísmo entre os alunos têm sido impostos à escola, sem que a mesma possa efetivamente atuar para evitar que os alunos faltem às aulas. A mais recente forma de controle está associada à política assistencial, adotada com as famílias de baixa renda, maioria nas escolas públicas - a bolsa família. Esta política social tem como condicionante a presença do aluno, nesse caso, atrelada ao recebimento da bolsa família pelo seu responsável.

O que observamos, de modo geral, nas escolas pesquisadas pelo netEDU, em 2009 e 2010, é o fato de que as escolas estão 'maquiando' os dados de frequência de seus alunos, atribuindo-lhes uma frequência total, independente da registrada pelos professores. Como justificativa, o argumento é de que "não podem agravar ainda mais a situação de pobreza dessas famílias". A frequência assim declarada, nada tem a ver com a real presença do aluno às aulas, mostrando, mais uma vez, que políticas assistenciais inseridas no interior da escola contribuem para demonstrar a sua incompetência e fomentar um sistema de 'faz de conta', comumente atribuído à área da Educação.

Esta temática não é preocupação deste capítulo, foi citada apenas a título de ilustração, para salientar o modo como são exercidos os mecanismos de controle sobre o absenteísmo 
(faltas de alunos), assim como os 'novos' processos de avaliação, e/ou a qualidade das aulas oferecidas às classes menos favorecidas que frequentam as escolas públicas.

Isto evidencia, mais uma vez, que a escola ainda não se deu conta da entrada deste grupo socialmente desfavorecido. Ela continua a perpetuar um ideário elitista, de forma alienante, no qual interpreta o aluno e suas famílias como sendo os culpados pelas dificuldades e desencontros culturais existentes na mesma.

\section{Absenteísmo e instâncias reguladoras}

Estabelecida a relação entre o absenteísmo escolar, a repetência, a delinquência juvenil, o fracasso escolar e a exclusão educacional, podemos questionar: o que está acontecendo no universo escolar para prevenir ou inibir o absenteísmo entre os alunos?

Sobre o absenteísmo de alunos, a legislação brasileira estabelece, de acordo com a constituição, em seu Artigo 208, parágrafo $3^{\circ}$ que: "compete ao poder público recensear os educandos no Ensino Fundamental, fazer-lhes a chamada e zelar, junto aos pais ou responsáveis, pela frequência à escola" (BRASIL, 1988).

O Estatuto da Criança e do Adolescente (ECA), criado dois anos depois da carta constitucional, insere os Conselhos Tutelares Municipais (CTs) como instâncias a serem "comunicadas", em casos de faltas "injustificadas" e "elevados" níveis de repetência, uma vez "esgotados" os recursos escolares (BRASIL, 1990), o texto do ECA é o seguinte:

VII - Atendimento no Ensino Fundamental, através de programas suplementares de material didático-escolar, transporte, alimentação e assistência à saúde.

$\S 3^{\circ}$ Compete ao poder público recensear os educandos no Ensino Fundamental, fazerlhes a chamada e zelar, junto aos pais ou responsável, pela frequência à escola. 
Art. 55. Os pais ou responsável têm a obrigação de matricular seus filhos ou pupilos na rede regular de ensino.

Art. 56. Os dirigentes de estabelecimentos

de Ensino Fundamental comunicarão ao Conselho Tutelar os casos de:

I - maus-tratos envolvendo seus alunos;

II - reiteração de faltas injustificadas e de evasão escolar, esgotados os recursos escolares;

III - elevados níveis de repetência.

Ambos os textos, da carta magna e do ECA foram incorporados à Lei de Diretrizes e Bases da Educação Nacional, em 1996.

Lei $n^{\circ}$ 9.394/96.

Art. 24 - A educação básica, nos níveis fundamental e médio, será organizada de acordo com as seguintes regras comuns:

I - A carga horária mínima anual será de oitocentas horas, distribuídas por um mínimo de duzentos dias de efetivo trabalho escolar, excluído o tempo reservado aos exames finais, quando houver (BRASIL, 1996).

VI - o controle de frequência fica a cargo da escola, conforme o disposto no seu regimento e nas normas do respectivo sistema de ensino, exigida a frequência mínima de setenta e cinco por cento do total de horas letivas para aprovação;

Art. 12. Os estabelecimentos de ensino, respeitadas as normas comuns e as do seu sistema de ensino, terão a incumbência de:

VII - informar pai e mãe, conviventes ou não com seus filhos, e, se for o caso, os responsáveis legais, sobre a freqüência e rendimento dos alunos, bem como sobre a execução da proposta pedagógica da escola; (Redação dada a Lei $n^{\circ}$ 9.394/96 pela Lei $n^{\circ} 12.013$, de 2009). 
VIII - notificar ao Conselho Tutelar do Município, ao juiz competente da Comarca e ao respectivo representante do Ministério Público a relação dos alunos que apresentem quantidade de faltas acima de cinqüenta por cento do percentual permitido em lei. (Redação dada a Lei $n^{\circ}$ 9.394/96 pela lei 10.287/2001).

Portanto, para a aprovação, fica estabelecida a exigência mínima de setenta e cinco por cento (75\%) de frequência, do total de oitocentas (800) horas, ou duzentos (200) dias letivos. Isso dá ao aluno o direito de faltar às aulas até o limite de vinte e cinco por cento (25\%) do referido total, isto é, duzentas (200) horas ou cinquenta (50) dias letivos. Assim, é admitida para a aprovação, a frequência mínima de setenta e cinco (75\%) da frequência total às aulas e das demais atividades programadas pela escola. Da mesma forma, faltar cinquenta (50) dias letivos ou duzentas (200) horas de atividades implica na reprovação automática do aluno.

Entretanto, até atingir este limite, a lei determina que medidas sejam tomadas pela escola para prevenir a ausência do aluno. $\mathrm{O}$ controle da frequência dos alunos é uma delas, que geralmente ocorre durante o ano letivo. Bimestralmente, professores e dirigentes escolares discutem em Conselhos de Classe (COC) a frequência dos alunos. No COC verificamos que um tempo considerável da reunião é dedicado às análises da frequência de cada aluno e das possíveis implicações de suas faltas.

A atuação dos COCs dentro das escolas é regulamentada pelo Regimento Escolar. Neste caso, pela Secretaria Municipal de Educação do Rio de Janeiro (SME/RJ), que editou em abril deste ano (2010) a resolução que dispõe sobre o Regimento Escolar Básico de sua rede de ensino. O novo regimento, em seu Título V, regulamenta a organização pedagógica. No Capítulo VI trata da promoção e da frequência e logo a seguir, no Capítulo VII, trata do Conselho de Classe, dispondo sobre o seu funcionamento. $\mathrm{O}$ texto diz:

Art. 45. A promoção dos alunos dar-seá quando atingidos os padrões mínimos estabelecidos para cada série, relativos ao aproveitamento escolar e à frequência. 
Art. 46. O Conselho de Classe é o espaço democrático de tomada de decisões acerca do Projeto Político-Pedagógico da Escola, do fazer pedagógico na sala de aula e do desenvolvimento da aprendizagem do aluno.

Art. 47. Caberá ao Conselho de Classe:

I - realizar a auto-avaliação da unidade escolar, enquanto instituição social, possibilitando a revisão de seu Projeto Político-Pedagógico; II - realizar análise diagnóstica da turma;

III - discutir o processo pedagógico desenvolvido com as turmas, visando o seu aperfeiçoamento;

IV - analisar o desenvolvimento da aprendizagem dos alunos;

V - acompanhar o desenvolvimento das atividades pedagógicas propostas para potencializar o aproveitamento dos alunos;

VI - verificar a situação de frequência dos alunos, procurando-se estratégias para evitar a evasão e reprovação por esse motivo.

Art. 48. O Conselho de Classe é constituído por:

I - Direção da Unidade Escolar;

II - Equipe Pedagógica;

III - Todos os professores regentes de turma;

IV - Representantes do Conselho Escola Comunidade - CEC;

V - Representantes do Grêmio Estudantil;

Parágrafo único. O Conselho de Classe é autônomo, mas não é soberano.

(Resolução SME $N^{\circ} 1073$ de 14 de Abril de 2010)

Portanto, o COC é responsável, não somente pela decisão conjunta sobre a frequência do aluno, como também pelo seu acompanhamento e pela avaliação de seu aproveitamento. Assim, é nesse momento, que a decisão de comunicar aos pais e aos CTs sobre o absenteísmo dos alunos é tomada. 
Muito se tem discutido a respeito da função dos CTs, apontados como mais uma instância de "encaminhamento" de alunos considerados "problemas”, marcados pela ausência das aulas ou por problemas de outra natureza. Sobre a atuação do Conselho Tutelar, um estudo realizado por Sousa e seus colaboradores (2003) demonstra que:

uma das prerrogativas do ECA refere-se à responsabilidade conjunta da escola e do CT no que se refere às ausências de alunos à escola. A escola deve comunicar ao Conselho Tutelar os casos de crianças que estão faltando muito, fornecendo-lhe nome, série e endereço, para que seus pais sejam notificados, visando saber a razão das faltas. Quando os pais não comparecem ao $\mathrm{CT}$, os conselheiros podem realizar visitas domiciliares, visando esclarecer os motivos. Independentemente de qual seja a razão das faltas, os conselheiros esforçam-se para que a criança ou o jovem volte a frequentar as aulas, conscientizando-o e à sua família sobre a importância da escolarização. Se há algum problema específico com aquela classe ou aquela escola, o conselheiro pode transferir o aluno para outro estabelecimento de ensino (idem, p.73).

Sousa e os demais autores registram a insatisfação dos Conselheiros que reclamam sobre a displicência das escolas, em relação às faltas dos alunos. Segundo os mesmos a escola deveria encaminhar os dados dos alunos que apresentam faltas injustificadas, antes que eles atingissem o limite de vinte e cinco por cento (25\%). De acordo com os Conselheiros esta displicência está relacionada ao sistema de ciclos e à progressão continuada, situações nas quais “o aluno passa sem saber”. Este dado também é evidenciado pelas denúncias que o CT recebe sobre "alunos que frequentam o sexto e o sétimo ano e não sabem escrever” (p.75).

O estudo de Sousa e de seus colaboradores (2003, p.74) analisou $34,8 \%$ (trezentos e setenta e quatro prontuários) do total existente no CT pesquisado, $73 \%$ desses relatavam queixas 
provenientes de pais de alunos e, 27\%, queixas das escolas. Tal fato sugere que a procura dos pais para solucionar os problemas relacionados à escola é três (3) vezes superior ao da escola para resolver os problemas de seus alunos com os pais.

Ao analisar os gráficos subtraídos do estudo de Sousa (idem) visualizamos os motivos das queixas apresentadas aos CTs investigados, o quantitativo das mesmas, os níveis educacionais a que estão relacionadas, as relações de gênero, dentre outros.

Gráfico I - Frequência das demandas escolares no conjunto de prontuários com informações sobre escolaridade (amostra = 130).

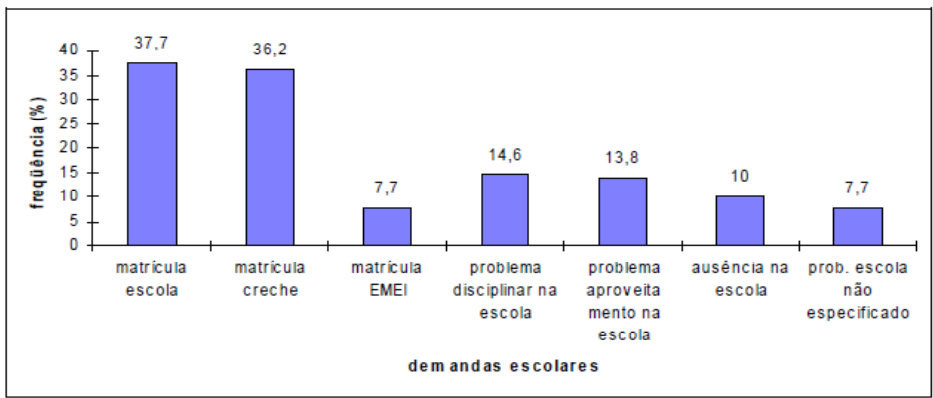

Fonte: Sousa e cols., 2003.

Gráfico II - Frequência de queixas relacionadas a aproveitamento na escola em função do gênero (amostra = 18).

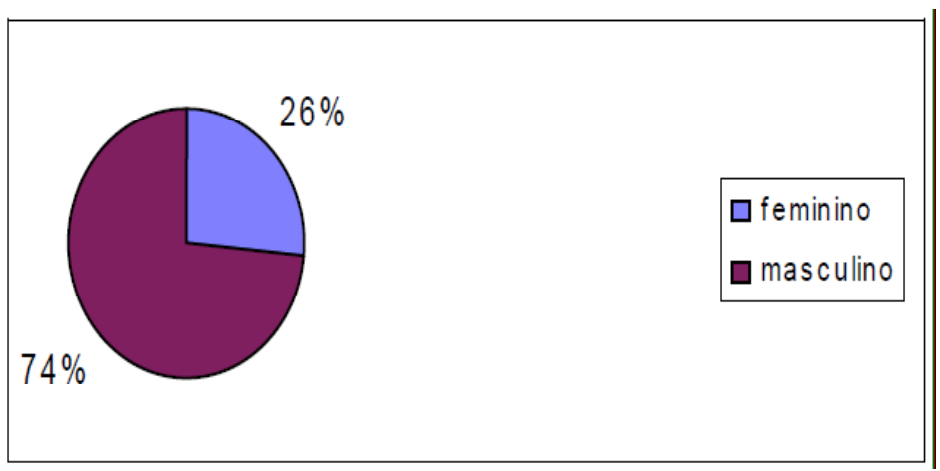

Fonte: Sousa e cols., 2003. 


\section{3}

Gráfico III - Frequência de queixas relacionadas a problemas disciplinares na escola em função do gênero (amostra =19).

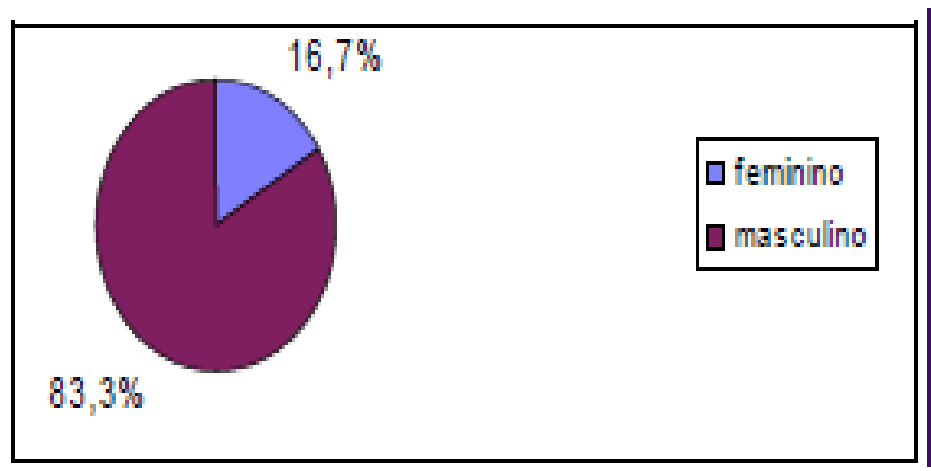

Fonte: Sousa e cols., 2003.

Gráfico IV - Frequência de modalidades de queixas referentes a problemas na escola

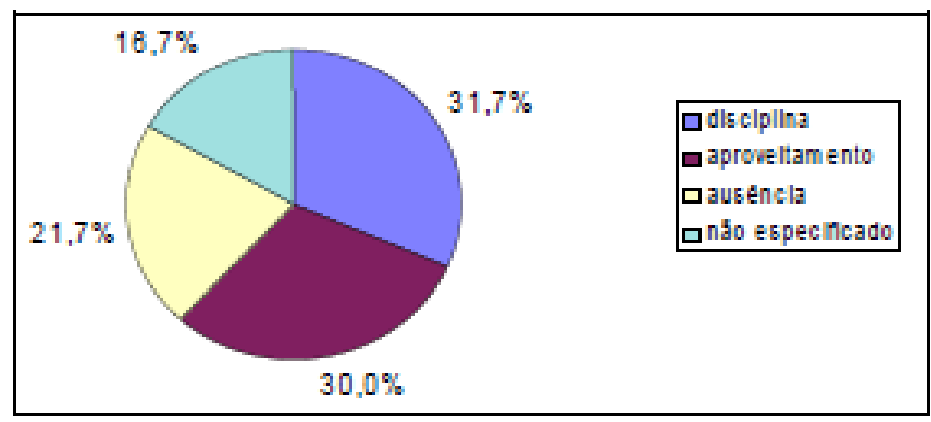

Os dados indicam que as faltas representam 10\% das queixas encaminhadas pelas escolas. As queixas disciplinares representam 14,6\%, do total dos prontuários analisados, deste total, 74\% estão relacionadas aos meninos e, $26 \%$, às meninas. Os problemas com aproveitamento escolar representam 13,8\% das queixas. Os meninos aparecem como responsáveis por $83,3 \%$, enquanto as meninas, por $16,7 \%$.

De um modo geral, no gráfico quatro (4), estão representadas as queixas quanto à disciplina (31,7\%); ao aproveitamento (30,0\%); à ausência (21,7\%) e por razões não especificadas $(16,7 \%)$. 
Estes gráficos demonstram o papel do CT como instância reguladora da escola, dos alunos e dos pais. Entretanto, verificamos em muitos casos que estes CTs também encontram dificuldades em lidar com os problemas que lhes são apresentados. Nas escolas pesquisadas pelo netEDU, alguns alunos referem-se aos membros dos CTs como 'os home', o que significa que têm medo destas pessoas, uma vez que se reportam a elas do mesmo modo que à presença dos policiais em seus locais de moradia (favelas). Nesta pesquisa foram ouvidos ainda diretores e professores, ressaltando a falta de qualificação e representatividade comunitária dos membros destes CTs.

No caso da classe de repetentes da turma C, os professores, em conselhos de classe, geralmente demonstravam preocupação com o excesso de faltas de seus alunos. Uma das professoras comenta:

Eu acho que seria uma responsabilidade muito grande da escola, uma responsabilidade muito grande nossa, né? Aprovar com esse número imenso de faltas.

Durante essas reuniões, a interpretação dos professores sobre o número excedente de faltas dos alunos variou muito. Vários foram os motivos apresentados, entre eles: as relações familiares, a higiene, a saúde e a violência. A família foi mencionada inúmeras vezes como culpada pela ausência do aluno, sendo também responsabilizada por não acompanhar os filhos na escola durante o ano letivo.

As queixas das escolas sobre a falta de envolvimento dos pais nas atividades escolares e nos problemas dos filhos são recorrentes nos estudos sobre a frequência e indisciplina dos alunos. Estas queixas, em sua maioria, refletem a justificativa dos pais sobre os horários disponíveis para este envolvimento, feito que exigiria dos mesmos a ausência ao trabalho.

Os pais, por outro lado, queixam-se das escolas pelo fato de que, quando são chamados, geralmente é para receberem alguma reclamação sobre os filhos. Aos olhos dos pais parece existir uma "soberania do saber escolar", espécie de poder que estaria acima deles e de seus conhecimentos a respeito 
dos filhos (SILVEIRA, 2007, p. 64). Esta soberania revela-se, em especial, através das orientações que a escola oferece à família, a respeito do comportamento das crianças e da ideia de que possuem um saber técnico e profissional sobre a educação da criança. Nesses encontros, chega-se a questionar a natureza das relações conjugais destes pais, muitas vezes interpretadas como fonte para os problemas de seus filhos.

Em sua tese a mesma pesquisadora salienta que, nas relações entre a família e a escola, os bilhetes são a forma mais usual de comunicação e que estes "possuem um caráter 'delator', queixoso e punitivo por parte do professor" (SILVEIRA, 2007, p. 64).

As relações entre a família e a escola foram analisadas por estudos realizados por Viana (2005; 2006; 2007 e 2009) e por Thin (2006): eles indicam que, muitas vezes, a escola da rede pública oferece um contexto social diferente daquele que o aluno vivencia com a família, esta exposição simultânea a culturas divergentes pode gerar uma crise cultural no aluno. Para Viana (2007) as dificuldades vividas pelo aluno podem se desenvolver em dois campos: "aquelas vividas no contexto da experiência escolar e as vividas no bojo das relações familiares" (p. 55). A autora acrescenta que o aluno pode autodeterminar o investimento que faz em sua escolaridade, quase sempre, contando com a colaboração dos familiares, pessoas que "participam da construção do sucesso escolar dos filhos de modo diferenciado, nem sempre facilmente visível e voltado explícita e objetivamente para tal fim" (VIANA, 2007, p. 58).

Além disso, o aluno também conta com a participação da escola para a construção do seu conhecimento. Viana (2006) explica que as três esferas: família, aluno e escola são diferenciadas e interdependentes, e podem contribuir para o sucesso escolar do aluno. Neste tópico, acrescenta-se a autoculpabização dos alunos e de seus pais sobre os seus resultados. Em relatório, Sousa e seus companheiros de pesquisa (2004 p. 36) explicam,

em síntese, as pesquisas que realizaram estudos de caso revelam a dificuldade dos professores para re-significar a avaliação da aprendizagem, mantendo como suas 
principais finalidades decidir quanto à aprovação dos alunos ao término dos ciclos e definir quais deles deverão fazer a recuperação paralela e de férias. A manutenção, na prática, do caráter punitivo e classificatório da avaliação, também se evidencia nas manifestações de alunos. A partir de entrevistas com alunos da rede estadual, Arcas (2003) assinala que estes se posicionam como responsáveis pelos resultados que obtêm na escola, considerando as eventuais notas baixas como decorrência do fato de que não estudaram ou do acompanhamento não satisfatório de sua trajetória escolar por parte da família (SOUSA, 2004 p. 36).

Um estudo de Ireland (2007) apresenta os casos de doença e as chuvas como às justificativas mais usadas pelos alunos e por seus pais para explicar as faltas à escola. Ao lado delas aparecem também: as questões familiares, a falta dos docentes e 0 trabalho doméstico que realizam. Percebemos, com isso, que os motivos são variados para justificar as faltas dos alunos. A análise realizada por este estudo acrescenta ainda que a falta dos alunos é justificada, por parte dos professores, por razões que passam pelas questões familiares, de higiene, de saúde e de violência.

\section{Justificativas e indicadores para o absenteísmo entre os alunos e alunas: evidências da pesquisa da pesquisa de campo realizada}

Mediante a fala dos sujeitos da pesquisa foi possível perceber que a família era constantemente responsabilizada pelos professores e dirigentes pelo baixo desempenho dos alunos, assim como pelas faltas às aulas. Em entrevista, a professora Carla afirma que são poucos os pais que demonstram interesse pelo desempenho escolar dos filhos, visto que muitos deles apresentam problemas sociais.

É... uma outra mãe que vem, que participa da reunião, para a mãe vir até a escola a gente teve que insistir muito ou impedir do aluno vir 
para a escola, são problemas sociais mesmo $e$, ás vezes, assim falta de interesse do pai mesmo, é.. falta de... é... Como é que eu vou dizer? Essa falta de interesse passa pela... falta de instrução dos pais também que é a questão social, né?

...famílias envolvidas com drogas tá, é... [...] crianças que moram com padrasto e é... brigas familiares com a mãe, com o pai, e com o padrasto, é... tem até um caso de prostituição, um caso de prostituição infantil na turma, é... tem casos de higiene seriíssimos, seriíssimos...

A exploração sexual infantil e a saúde, ligada à higiene, também são apontadas como possíveis causas da ausência de uma das alunas, da classe de repetentes da turma C. O nome da aluna (Cláudia, de 11 anos, quatro vezes repetente) foi levado ao COC, considerando o fato de que a mesma possuía noventa e sete (97) faltas. Na ocasião foi sugerido que a aluna buscasse tratamento para alguns problemas de saúde derivados da falta de higiene, tais como: piolho e sarna; motivo de suas faltas, agravadas pela vergonha, uma vez que foi obrigada pela família a cortar o cabelo muito curto, contribuindo com isso para que ela perdesse o interesse de voltar para escola.

De acordo com a professora Sônia, foi necessário ir à casa da aluna, conversar com a avó da menina, para que a mesma retornasse às aulas. A conversa sobre o tema foi a seguinte:

Eu fui buscar ela em casa, porque a escola sugeriu que ela ficasse em casa pra tratar do piolho e da sarna e não voltou nunca mais, tanto que deu 97 faltas e eu fui até a casa dela pra saber se ela tinha morrido né? Aí cheguei lá, conversei com a avó, falei, falei, falei, desde então, ela não faltou nunca mais.

Ela teve sarna e ela teve, não justifica as 97 ta, mas ela teve sarna e ela teve piolho. E nós sugerimos, foi até uma das falas na casa dela, ... mas não fomos nós que não deixamos ela ir na escola, foi a escola que sugeriu..., aí eu 
falei: 47 dias? Porque aí não é possível, ela tem um histórico também, eu já fui preparada pra isso. Mas a justificativa é que, não temos como atestar, eu não sei se isso serve também pra justificar, mas ela teve sarna e piolho e precisou ficar em casa pra se tratar, tanto que ela raspou a cabeça.

Evocê sabe também por que ela não está vindo, porque ela não tratou o piolho, ela raspou a cabeça, tanto que eu comprei umas xuxinhas pra ela, ela falou: tia, tá ridículo!, ela fica com aquela touca, eu falei: Larissa, pelo amor de Deus, larga essa touca, olha o cheiro.

Cláudia que ficou afastada é [...] ficou afastada da escola para tratar a sarna, que ela estava com sarna e com piolho, né! Teve até que raspar a cabeça, e está usando touca o tempo inteiro.

Mariane, uma aluna de nove anos de idade, da classe da turma $\mathrm{C}$, questionada se tinha problemas com faltas, respondeu sucintamente que não, passando a falar do caso da colega de turma. Ela disse "Não, quem falta muito é a Claúdia. [...] Ela tava com piolho, ela raspou a cabeça, por isso que ela fica com a touca. Vê só aquele negócio de chamada tem muita falta dela..."

Ao caso da menina Cláudia, a professora Cássia acrescenta o fato de que a mãe da aluna tem um histórico de surtos e responsabiliza a avó da menina pelos problemas da mesma. No mesmo encontro outras professoras mencionam a família de Cláudia, acrescentando que têm conhecimento de que a menina tem sido forçada pela família a se prostituir. A conversa foi a seguinte:

Ah, ela tem uma história. Em 2005: Crianças afastadas da escola por motivos de problemas familiares. Mãe apresentou surto psicótico pedindo a saída das crianças. As crianças estão com a avó (em 2005). Crianças estão sem uniforme porque a mãe rasgou o uniforme. [...] A mãe dela também tem um problema muito sério de.... de... é problemas neurológicos, 
ela surta de vez em quando né? E.... isso tudo afeta com certeza, com certeza, eu acho que isso né? Não tem dúvida. [...] Essa família, ela é completamente largada, jogada, a mãe não sabe nada, a avó não tem nenhum interesse, e eu não sei... [...] Fica eu e o pedreiro dali, a gente fica só olhando, é um velho de bicicleta que a mãe da Cláudia vai, pega o dinheiro com ele, aí essa semana eles estavam discutindo aqui na esquina porque o velho não queria dar o dinheiro, aí o vizinho também da frente está achando que esse senhor... ela tá usando a filha entendeu?Está vendendo. Prostituindo a filha..[... ] Tem até um caso de prostituição, um caso de prostituição infantil na turma.

Apesar dessa situação, a professora Maria defende a ideia de que a menina "tem conteúdo suficiente para ser promovida para a segunda série”. E mesmo com toda a discussão sobre as condições pessoais da vida da menina, termina por aprová-la. Embora a professora tenha sido questionada por alguns professores, com o argumento de que esta talvez não fosse uma “decisão acertada”, pois a família da menina continuaria desinteressada e isso poderia dar continuidade às faltas.

Pode-se inferir que embora existisse a possibilidade de reprovação automática da aluna Cláudia, pelo COC e pela professora Maria, a menina não foi reprovada, o que indica que as formas de avaliação não são pautadas nas regras legais, essas só se aplicam nos casos em que tanto a professora da classe quanto o COC tem intenção de usá-las como justificativa, como poderá ser visto em alguns casos que citaremos a seguir. No caso da classe da turma $\mathrm{C}$, o que contou para a promoção da menina foi o fato de que a mesma provavelmente dominava a leitura e a escrita, saindo-se melhor que os demais alunos. Portanto, neste caso, o mérito acadêmico prevaleceu.

As violências físicas e verbais na sala de aula contribuem, sobremaneira, para o absenteísmo entre os alunos. A aluna Amanda, de nove (9) anos de idade, foi um desses casos evidenciados na classe da turma $C$, no qual a violência motivou 0 desinteresse pela escola, resultando em cinquenta e dois (52) 
dias letivos de faltas. O nome de Amanda foi citado no COC, uma vez que se deveria decidir sobre o seu destino acadêmico, visto que a mesma ultrapassara o limite de $25 \%$ de faltas. A conversa no COC foi a seguinte: "Amanda, ela está com 52 faltas, mas ela... Ela lê, entende, ela escreve sobre sequência lógica”.

Durante o COC não foi mencionado o motivo do absenteísmo da Amanda, mas em entrevista ela justificou que os colegas batiam nela e a ameaçavam. A conversa com Amanda obteve as seguintes respostas:

É muito difícil. Minha mãe fala quando eu venho pra escola, que é pra eu não brigar. E eu não brigo. Porque senão outros podem me bater. [ mas] Pararam já. Quem batia era o João, Lúcio, Alexandre, Sandro. Só porque naquele dia sem querer, eu entornei um copo e molhei o celular da tia, eles estavam querendo me bater na rua. Saí correndo pra casa, porque eles falaram que iam me pegar.

Ao relacionar as faltas com a violência que sofre, a menina disse:

Eu faltava muito, mas agora eu tô vindo todo dia. Eu não gostava de vir pra escola não. Não gostava não, era muito ruim. Porque os garotos estavam querendo me bater, e minha mãe não mandava eu vir pra escola. Só às vezes quando os meninos não estavam na escola, ela mandava eu vir.

Da mesma forma que no caso anterior, as faltas de Amanda foram 'relevadas'; tanto pela professora Maria quanto pelo COC. Ela foi aprovada, apesar das considerações feitas pelas professoras sobre o caso da menina. A argumentação do COC foi a seguinte:

Gente, a mesma frequência do ano passado, ano passado ela foi reprovada porque tinha 51 faltas, $74 \%$. Mas aí também não foi só isso. Apresenta extrema dificuldade com a leitura, então não foi só por frequência, ela faz atendimento? [... ] Não, ô Cássia, Roberta irmã dela 
também foi reprovada por frequência, Roberta é irmã dela, foi reprovada por freqüência, e ela também tem problema de frequência. [...] 2004 ela foi reprovada na nível um, por frequência. Quando chegou em 2005 ela foi aprovada. Em 2006 ela foi reprovada, não por frequência, ela teve $75 \%$, mas ela foi reprovada por conteúdo, então esse ano já é o terceiro de escolaridade. $E$ aí ano passado ela ficou por frequência e... [...] Agora eu vou ficar mais com a fala da Professora Maria de que ela quer melhorar. Depois da conversa que você teve com ela, ela evita de faltar não é? É. Podia dar uma chance! Você acha que ela tem condições? Tem. Porque ela... leu razoavelmente bem... É, então... E ela tá com 52 faltas é muito pouco, ainda mais no histórico que ela tem.

Constatamos que a menina foi aprovada por ter ultrapassado o limite por "poucas" faltas, apenas cinquenta e duas (52). Vale a pena questionar o que pode ser considerado muito ou pouco, quando temos um mínimo a ser cumprido, ou descumprido, no caso das duas meninas mencionadas anteriormente, Cláudia e Amanda.

Alexandro, menino de dez (10) anos, assim como as alunas anteriores, foi mencionado no COC por ter faltado cinquenta e seis (56) dias letivos durante o ano. Neste caso, o número de faltas, contrário aos outros citados, foi considerado muito elevado. O motivo levantado pelo COC foi a indisciplina do aluno, em sala de aula, assim como a sua origem familiar, pois as professoras argumentaram que a convivência com uma família 'violenta' era responsável pelo mal comportamento do menino. A conversa sobre o caso de Alexandro pode ser transcrita assim:

Alexandro. Também tem 10 anos. É repetente. Ele está com 56 faltas, e ele vem pra escola, faz o que quer, e ele não aceita ser contrariado, bate na cadeira, se joga no chão. E ele lê? Ele lê, mas na hora de escrever... por exemplo, "balão" ele já escreve. Se falar bem pausado né. É, bem pausado. Também o que? Tem 11 anos! 10 ! E é o segundo ano dele, ta no segundo ano 
de escolaridade... Chato que já tem sérios problemas né. É. Quem é favorável à reprovação do Alexandre? (Todos os presentes levantam as mãos) [...] Com toda essa problemática familiar dele também. É, mudança também de... Pois é, e esses hábitos adquiridos que ele está né? De todo esse histórico está bastante... não, como vai ser ano que vem, não.

Em entrevista, as professoras relataram assim o caso de Alexandro:

A questão do Alexandro, o Alexandro na verdade perdeu mais por frequência né? Ele foi retido por frequência pela dificuldade dele, ele até sabe ler, sabe escrever, não está ainda, é vamos dizer assim é... como aluno de terceiro ano que é pra onde ele iria, mas a dificuldade no Alexandre, essa reprovação dele foi mais proveniente das faltas dele tá?”

"O Alexandro, ele é vive em um ambiente de... é... de drogas e é... roubo é...vive também a mãe com o padrasto, e a mãe esteve essa semana aqui na escola e disse que o pai ameaçou de matá-la com facas e ele com o irmão menor é que foram chamar a polícia. Acredito que todo esse é envolvimento familiar, essa... não ter um ambiente é... um ambiente tranqüilo não é, é.. isso faz com que o seu... e com certeza também ele apresenta algumas questões neurológicas que nós já.. já é... solicitamos que fizesse os exames e ela até hoje não fez né? E o papel da escola assim está sendo feito, tudo registrado, tudo assinado pela mãe também, todas as questões, é... o Alexandre já apareceu na escola com alguns objetos que foram roubados, nós solicitamos a presença da mãe e devolvemos nas mãos da mãe, acredito que tudo isso é...

Alexandro, entretanto, tem outra versão para o absenteísmo nas aulas da professora Maria. Em entrevista, tanto ele como seu colega de classe, Felipe, afirmaram muitas vezes que 
faltaram as aulas por conta do absenteísmo da professora. A fala dos meninos pode ser transcrita assim:

Ontem eu faltei porque eu fui pra minha tia e não trouxe meu material porque não tinha aula. Alexandro: A tia faltou. (Todos foram foi embora?) Sim. (tem outra professora para substituir?) Não. (Felipe tem alguma coisa que você gosta na professora?) Tem, porque ela falta aula. Às vezes.

Observamos nas discussões do COC que somente o absenteísmo dos alunos é levado em conta, a falta das professoras não foi mencionada. No caso do Alexandro, o que contou para a sua reprovação foi a associação de dois fatores: a indisciplina em sala de aula e o histórico familiar. Sobre problemas familiares, muitos casos foram mencionados no COC. Em entrevista, uma professora resume a percepção do grupo sobre o tema:

a maioria dos pais não tem interesse em acompanhar o desenvolvimento dos filhos. Acho que também tem, tem essa coisa da família, da família em casa procurar: meu filho tem algum dever de casa? Vamos sentar, vamos ver, vamos ler. Eu acho que esse apoio eles não tem em casa, a maioria, a maioria.

Ficou evidente nas análises derivadas desta pesquisa, no que tange ao absenteísmo escolar, que os estudos apresentados, de fato, puderam ser comprovados; pois as justificativas mais comuns para o absenteísmo foram: a pobreza, associada à falta de saúde e às questões de higiene e à violência aos problemas familiares.

Entretanto, apesar de existirem regras definidas, leis e órgãos reguladores sobre o absenteísmo escolar, as análises realizadas revelam que estes não são considerados. A "autonomia relativa dos COCs”, prevista no regimento escolar, foi transformada, nos casos analisados, em “ lei da escola”, uma vez que a soberania da decisão fica nas mãos dos professores, que justificam através do COC, com os mesmos argumentos legais, decisões diferentes. O caso desta escola assemelha-se 
muito às decisões judiciárias no Brasil, pois para quem tem capital econômico a lei é uma e para os pobres e desvalidos, a lei é outra. Tudo depende da vontade do poder público de gerenciar com 'justiça' e 'isenção' o caso que tem em mãos.

No presente capítulo, observamos que por conta de uma lei determinada pelo MEC, os alunos que não cumprirem $75 \%$ de frequência devem ser automaticamente reprovados. Entretanto, na classe de repetentes da turma C, a quantidade de faltas não é um fator que pode levar à reprovação, considerando que alunos com alto índice de absenteísmo foram considerados aptos ou inaptos para a série seguinte, tendo sido avaliados de formas diferentes pelo conselho de classe da Escola João Pedro II. Os critérios utilizados para a aprovação e/ ou reprovação não foram explicitados durante o conselho de classe, por isso, a pesquisadora não pôde definir claramente quais foram os critérios usados para aprovar ou reprovar um aluno, com um alto índice de faltas. 


\section{Referências}

BRASIL. Lei no 9.394. Estabelece as Diretrizes e Bases da Educação Nacional, de 20 de dezembro de 1996. Presidência da República. Brasília, DF

BRASIL. Constituição da República Federativa do Brasil. Presidência da República. 5 de outubro de 1988. Brasília, DF

BRASIL. Estatuto da Criança e do Adolescente, Câmera dos Deputados, Lei no 8.069, de 13 de julho de 1990. DOU de 16/07/1990 - ECA. Brasília, DF.

CANDAU, V. M. Direitos humanos, educação e interculturalidade: as tensões entre igualdade e diferença. In: Revista Brasileira de Educação, v. 13, n. 37, p. 45-56, 2008.

CHOUQUET, M.; HASSLER, C. Absentéisme au Lycée. Les dossier D'Education et Formations. Ministère de l'Éducation Nationale, de La Recherche et de la Technologie. Paris, France: 1993

FLETCHER, R.P., RIBEIRO, S.C. A educação na estatística nacional. In: SAWYER, D. O. (org.). PNADs em foco: anos 80. Belo Horizonte, Associação Brasileira de Estudos Populacionais - ABEP.

Galloway, D.; Seyd, R.; Ball, T. Absence from school and behavior problems in school therapeutic education. London: Pergamon Press, 1978.

GOUVÊA, G. F. P. Um Salto para o presente: a educação básica no Brasil. São Paulo em Perspectiva, v.14, n.1, 2000.

IRELAND, V. E. (coord.); CHARLOT, B.; GOMES, C.; GUSSO, D.; CARVALHO, L. C. R. de; FERNANDES, M; ENNAFAA, R.; GARCIA, W. Repensando a escola: um estudo sobre os desafios de aprender, ler e escrever. Brasília: UNESCO, MEC/INEP, 2007.

KAFURI, R.; RAMON, S. P. Pesquisa sobre evasão, repetência e fatores condicionantes: relatório $-1^{\circ}$ grau, casos e percalços. Goiânia: UFG: FAE, 1985. 
MAINARDES, J. Organização da escolaridade em ciclos no Brasil: revisão da literatura e perspectivas para a pesquisa. Educação e Pesquisa. São Paulo, v. 32, n. 1, p. 1129, jan./abr. 2006.

NERI, M. C.; COSTA, D. R. da. O Tempo das crianças. Rio de Janeiro: Fundação Getúlio Vargas, 2002 (Ensaios Econômicos, 468).

PAZELLO, E.T.; FERNANDES, R.; FELICIO, F. Incorporando o atraso escolar e as características sócio-demográficas nas taxas de transição educacional: um modelo de fluxo escolar. Anais do XXXIII Encontro Nacional de Economia, ANPEC, 2005.

REID, K. C. Alienation and persistent school absenteism.

Research in Education, v.29, p.31-40, 1981. 